\title{
OS PARADIGMAS ACERCA DOS DIREITOS DAS PESSOAS COM DEFICIÊNCIA: PARA ALÉM DA DISTINÇÃO ENTRE EXCLUSÃO E INCLUSÃO
}

\author{
José Alberto Antunes de Miranda ${ }^{1}$ \\ Reynaldo Alan Castro Filho 2
}

RESUMO: O artigo abordou os diferentes paradigmas acerca dos direitos das pessoas com deficiência, adotados pela legislação internacional e nacional. A metodologia utilizada foi análise documental e revisão bibliográfica. Nesse contexto, verificou-se que o paradigma da integração toma por base a ideia de que são as pessoas com deficiência que devem adaptar-se aos sistemas sociais comuns, ao passo que o paradigma da inclusão pressupõe que a sociedade deve passar por adaptações. Conclui-se que nem mesmo a inclusão afastar-se-ia da tendência de reproduzir a desigualdade enraizada nos países periféricos, o que justifica avançar para além da distinção clássica entre exclusão e inclusão.

Palavras-Chave: Direitos; Exclusão; Inclusão Social; Integração Social; Pessoas com deficiência.

\section{THE PARADIGMS ON THE RIGHTS OF PERSONS WITH DISABILITIES: BEYOND THE DISTINCTION BETWEEN EXCLUSION AND INCLUSION}

\begin{abstract}
This paper described the different paradigms on the persons with disabilities rights adopted by the international and national legislation. For this, the methodology was the documentary analysis and the bibliographic review. In this context, it has been found that the integration paradigm is based on the idea that people with disabilities must adapt to common social systems, while the inclusion paradigm presupposes that the society must suffered adaptations to reply the needs of people who are excluded from common social systems. However, even inclusion would not depart from the tendency to reproduce the inequality rooted in peripheral countries, which justifies moving beyond the classical distinction between exclusion and inclusion.
\end{abstract}

Keywords: Rights; Exclusion; Social Inclusion; Social Integration; Disabled People.

\footnotetext{
${ }^{1}$ Possui graduação em Direito pela Universidade do Vale do Rio dos Sinos (1996), Especialização em Integração e Mercosul pela UFRGS (1999), Mestrado em Relações Internacionais pela Universidade Federal do Rio Grande do Sul (2004) e Doutorado em Estudos Estratégicos Internacionais pela UFRGS (2012). Atualmente é Assessor de Assuntos Interinstitucionais e Internacionais e professor permanente do Mestrado em Direito e Sociedade além de integrar o corpo docente do Curso de Relações Internacionais da Universidade La Salle. Tem experiência na área de Relações Internacionais, com ênfase em Política Externa e Análise da Política Externa, Integração Regional, Organizações Internacionais, Direito Internacional, Constituição e Relações Exteriores e Internacionalização da Educação Superior. <jose.miranda@unilasalle.edu.br>

${ }^{2}$ Mestrando em Direito da Universidade La Salle. Graduado em Ciências Jurídicas e Sociais pela Pontifícia Universidade Católica do Rio Grande do Sul (2008). Possui Especialização em Direito do Estado pela Universidade Federal do Rio Grande do Sul (2010) e Especialização em Direito Internacional Público e Privado também pela mesma instituição (2014). Atualmente é técnico-administrativo da Universidade Federal do Rio Grande do Sul e atua na análise de processos administrativos de servidores técnicos e docentes em questões que envolvam aplicação da legislação de pessoal no âmbito da Universidade. Tem experiência na área de Direito, com ênfase em Direito Administrativo. <racfcastro@gmail.com>
} 


\section{INTRODUÇÃO}

O presente artigo abordará os diferentes paradigmas adotados à luz da legislação internacional e nacional no que concerne a evolução dos direitos das pessoas com deficiência de acordo com os diferentes momentos históricos. Considerando que o atual paradigma adotado é o da inclusão social, o artigo procurará, ainda, desconstruir a dicotomia clássica existente entre o binômio exclusão/inclusão, levando em consideração a existência de outras variáveis que decorrem da complexidade da sociedade atual. Para tanto, o estudo dividir-se-á em quatro partes.

A primeira parte cuidará da construção histórica dos direitos das pessoas com deficiência, a fim de identificar os diferentes paradigmas adotados de acordo com o contexto vigente. Na ocasião, serão abordados os aspectos teóricos que compõe o paradigma da integração e o da inclusão.

No segundo momento, discorrer-se-á, pontualmente, acerca da evolução da legislação internacional destinada às pessoas com deficiência, no intuito de ilustrar a adoção dos paradigmas pelos diferentes documentos internacionais, que, conforme o enfoque e o contexto, baseavam-se no modelo da integração ou no da inclusão.

A terceira parte cuidará dos direitos das pessoas com deficiência no plano interno. Nesse ponto, será tratado acerca do status hierárquico da Convenção sobre os Direitos das Pessoas com Deficiência, quando incorporada ao ordenamento pátrio, bem como será identificado, a partir de análise de dispositivos constitucionais e infraconstitucionais específicos, a adoção de um, ou de outro paradigma, conforme o caso.

Por fim, tendo em vista a complexidade social que se apresenta na contemporaneidade, a última parte procurará desconstruir a distinção clássica que se apresenta entre os termos exclusão e inclusão, uma vez que existem variáveis para além dessa distinção.

\section{Diferentes paradigmas acerca dos direitos das pessoas com deficiência}

A construção histórica dos direitos das pessoas com deficiência apresenta quatro fases distintas ${ }^{3}$, a saber: a) fase da eugenia (eliminação); b) fase do assistencialismo; c) fase da integração; e d) fase da inclusão.

\footnotetext{
${ }^{3}$ No tocante às diferentes fases históricas no tratamento conferido às pessoas com deficiência, verifica-se consenso quanto à existência de quatro fases. Contudo, em relação à denominação e à ordem cronológica de cada fase, não
}

Rev. de Direito Sociais e Políticas Públicas | e-ISSN: 2525-9881 | Porto Alegre | v. 4 | n. 2 | p. 1 - 21 | Jul/Dez. 2018 
A fase da eugenia marcou uma etapa de intolerância no tratamento às pessoas com deficiência, tendo em vista que a deficiência era tida como impureza ou castigo divino. Manifestou-se de forma preponderante na Antiguidade Clássica e, após um período de razoável moderação na Idade Média, foi retomada com força durante a era Nazifascista. Nessa fase, a deficiência era tida como maldição e a eliminação (morte) das pessoas com deficiência (até mesmo crianças) era algo visto como natural e, de certa forma, necessário.

Da era cristã ao período medieval vigorou a fase do assistencialismo. Em que pese o fato das pessoas com deficiência, nesse período, não serem mais vistas como "quase coisa", já que, por ser pecado, matá-las não era mais admissível, verifica-se que eram extremamente dependentes de uma política assistencialista. Apesar da caridade, esse grupo era segregado, separado do resto da sociedade, o que justifica identificar essa fase também como fase da invisibilidade (PIOVESAN, 2012).

Concernente à fase da integração, que se iniciou no Renascimento, em fins do século XIV, perdurando até início do século XVII, vale dizer que a deficiência era considerada uma doença e que, como tal, deveria ser curada. Nessa fase, não há que se falar em segregação nos moldes da etapa anterior. Não obstante, a discriminação continuou, uma vez que se buscava primeiramente a cura antes de permitir o convívio dessas pessoas com os demais. Tal fato, conforme salienta Lutiana N. Lorentz, não deixou de representar uma segregação, além do que não permitiu o desenvolvimento da ideia de superação dos obstáculos mediante um esforço conjunto (LORENTZ, 2016).

Segundo sustenta Romeu Sassaki (2004), o paradigma da integração social toma por base a ideia de que são as pessoas com deficiência que devem adaptar-se aos sistemas sociais comuns, de modo que, na hipótese de isso não ocorrer, por conta da suposta incapacidade dessas pessoas, seria necessária a criação de sistemas sociais especiais, separados dos demais, que fossem a elas destinados. Assim, de acordo com esse paradigma, nenhuma alteração significativa ocorre na estrutura da sociedade, que continua a oferecer, basicamente, os mesmos serviços.

Vale dizer, ainda, que durante a fase da integração social houve o desenvolvimento de conceitos considerados pré-inclusivistas, uma vez que serviram de referência para a evolução

se pode dizer o mesmo. Para analisar diferentes interpretações, ver LORENTZ, Lutiana Nacur. A norma da igualdade e o trabalho das pessoas portadoras de deficiência. 2. ed., São Paulo: LTr, 2016, p 74-144; e PIOVESAN, Flávia. Temas de direitos humanos. 5. ed. São Paulo: Saraiva, 2012, p. 174-183. 
do tratamento conferido às pessoas com deficiência, que foram: o modelo médico de deficiência e os princípios da normalização e do mainstreaming (SASSAKI, 1997).

No modelo médico, o foco concentra-se na deficiência, ou seja, as pessoas com deficiência são vistas a partir de suas incapacidades para realizar determinada atividade. Além disso, as pessoas com deficiência são tratadas como sendo diferentes dos demais cidadãos, uma vez que seriam incapazes de se autodeterminar. Dessa forma, o princípio fundamental deste modelo baseia-se na proteção das pessoas com deficiência, na medida em que estas poderiam desempenhar apenas o papel passivo de pacientes (CHAMBERLIN, 2005).

Por conseguinte, o modelo médico reforça a ideia de que a pessoa com deficiência é que precisa, num primeiro momento, de tratamento, a fim de que, posteriormente, consiga adaptarse aos sistemas sociais comuns. Noutros termos, a deficiência é vista como um problema exclusivo do indivíduo (FLETCHER, 1996).

Diante disso, há que se reconhecer que o modelo médico tem servido, em grande parte, de argumento a favor da resistência contra eventual necessidade de mudança nas estruturas dos sistemas sociais comuns, para que se permita, por meio da inclusão, que pessoas com deficiência possam alcançar desenvolvimento pessoal, profissional etc.

Já o princípio da normalização, conforme sustenta Eunicéia Mendes (1994), consiste na ideia de que toda pessoa portadora de deficiência tem o direito de experienciar um estilo ou padrão de vida que seria comum ou normal à sua própria cultura. Contudo, ao procurar normalizar padrões de vida, a normalização visava a mudar o comportamento das pessoas com deficiência para que estas se tornassem pessoas "normais".

Na prática, também produzia segregação, já que tinha por objetivo reproduzir ambientes muito próximos daqueles vivenciados pela população em geral, tais como escola, moradia, trabalho etc., desde que isso ocorresse em instituições destinadas ao atendimento das pessoas com deficiência em separado das demais.

No que toca ao chamado princípio de Mainstreaming, registre-se que se caracterizava por permitir a aproximação de alunos com deficiência dos serviços educacionais convencionais disponíveis na comunidade. Contudo, ainda que um aluno com deficiência pudesse estudar numa escola comum, o princípio referido entendia que a simples inserção física desse aluno em várias salas de aula, sem que a escola adotasse qualquer tipo de política inclusiva, seria uma medida eficaz. Por conta disso, frequentemente um mesmo aluno com deficiência assistia matérias de diferentes anos escolares, o que fazia com que, de fato, ele não pertencesse a nenhuma turma (ROBERTSON et al, 1995). 
Derradeiramente nesse contexto encontra-se a quarta e atual fase cronológica, a da inclusão, sendo apenas a primeira orientada sob a ótica dos direitos humanos. Essa fase tem seu marco inicial, na Europa, após a Segunda Guerra Mundial e, em países como os Estados Unidos da América e o Brasil, a partir das décadas de 1980 e 1990. O foco da inclusão concentra-se em permitir o convívio das pessoas com deficiência com o resto da sociedade, partindo-se da concepção de que a deficiência não deve ser tratada como doença, mas como manifestação da diversidade humana, o que pressupõe um esforço mútuo de todos, inclusive daqueles que não possuem deficiência.

Na verdade, a inclusão que está em jogo é a inclusão social, que, para além da causa das pessoas com deficiência, visa a tornar a sociedade, de modo geral, em um lugar que permita a convivência entre pessoas de todos os tipos e condições na realização de seus direitos, necessidades e potencialidades (SASSAKI, 2004). Diante disso, é mister que a sociedade passe por adaptações, a fim de atender às necessidades das pessoas que se encontram excluídas dos sistemas sociais comuns existentes.

\section{LEGISLAÇÃO INTERNACIONAL DAS PESSOAS COM DEFICIÊNCIA E PARADIGMAS ADOTADOS}

Os primeiros documentos internacionais específicos destinados à proteção das pessoas com deficiência remontam à década de 1970, que foram a Declaração dos Direitos do Deficiente Mental (1971) e a Declaração dos Direitos das Pessoas Deficientes (1975), sendo que esta última trouxe importante inovação no sentido de reconhecer, de forma explícita, as ONGs representantes das pessoas com deficiência como fonte de consulta em relação a seus direitos (PIOVESAN, 2012). Ainda no âmbito do Sistema Internacional de Proteção dos Direitos Humanos da ONU, destacam-se outros dois documentos que corroboraram o entendimento de que as organizações das pessoas com deficiência devem ser consultadas nos assuntos de seus interesses, quais sejam: o Programa Mundial de Ação para as Pessoas com Deficiência (1983) e as Normas sobre a Equiparação de Oportunidades para Pessoas com Deficiência (1993) (SASSAKI, 2004).

No que concerne às Declarações adotadas no âmbito da ONU, cumpre ressaltar que não se caracterizaram como normas jurídicas vinculantes, de modo que dependiam da vontade política dos Estados para que fossem cumpridas. Outro ponto a se destacar reside no fato de que ambos os documentos baseavam-se no modelo médico para definir o que seria deficiência 
(FERNÁNDEZ LIESA, 2007). Por oportuno, vale esclarecer que, diferentemente dos Tratados Internacionais, que criam, modificam ou extinguem direitos e obrigações entre dois ou mais Estados ou entidades internacionais, as Declarações não se constituem, em princípio, em fontes formais do Direito Internacional Público, uma vez que não geram direitos e obrigações entre os entes celebrantes.

Nesse contexto, ressalte-se a importância da Convenção Interamericana sobre a Eliminação de todas as formas de Discriminação contra Pessoas com Deficiência, adotada pela Organização dos Estados Americanos (OEA) em 1999, que, além de configurar-se como norma jurídica obrigatória, apresentou uma definição inovadora de deficiência, deixando de lado o enfoque médico para basear-se no aspecto social. Para a referida Convenção, a deficiência é definida "como toda e qualquer restrição física, mental ou sensorial, permanente ou temporária, que limita o exercício de direitos e que pode ser causada ou agravada pelo ambiente econômico e social".

Essa mudança de perspectiva teve como finalidade permitir a plena participação das pessoas com deficiência na sociedade, reconhecendo-se, no dizer de Carlos R. Fernández Liesa, "que las circunstancias de las personas com discapacidad y la discriminación que sufren son fenómenos creados por la sociedad” (FERNÁNDEZ LIESA, 2007, p. 64). Pela primeira vez admite-se que o meio ambiente econômico e social pode ser causa de agravamento da deficiência.

Dessa forma, a fim de universalizar a proteção dos direitos das pessoas com deficiência, foi aprovada, no ano de 2006, a Convenção Internacional da ONU sobre os Direitos das Pessoas com Deficiência. Vale dizer que a referida Convenção corroborou o enfoque social acerca da definição de deficiência quando estabeleceu, em seu artigo $1^{\circ}$, que "pessoas com deficiência são aquelas que têm impedimentos de longo prazo de natureza física, mental, intelectual ou sensorial, os quais, em interação com diversas barreiras, podem obstruir sua participação plena e efetiva na sociedade em igualdades de condições com as demais pessoas".

Verifica-se, com isso, que a sociedade não só deve produzir mecanismos para promover a inclusão das pessoas com deficiência a partir da ideia de que a deficiência não é doença, como também deve assumir a visão de que a deficiência é um conceito que não está centrado na pessoa, mas localizado na própria sociedade, que impõe limites e barreiras ao pleno desenvolvimento desses indivíduos.

Nesse sentido, conforme assinala Luiz A. David Araújo (2011), ainda que não se possa olvidar os critérios médicos ou psicológicos que permitam a constatação de uma falha sensorial 
ou motora, o elemento central que caracteriza a pessoa com deficiência não se relaciona com tais critérios, mas com a dificuldade dessa pessoa estar incluída na sociedade. Por conseguinte, é a dificuldade de inclusão social que define quem é ou não pessoa com deficiência.

Corrobora-se, dessa forma, que a deficiência não se localiza no indivíduo, e sim na relação que se estabelece entre este e a sociedade. A título de exemplo, cite-se o caso dos superdotados, que, mesmo possuindo inteligência e habilidades superiores aos padrões normais, apresentam, muitas vezes, dificuldades de adaptação, o que permite afirmar que dentre tais indivíduos também é possível encontrar pessoas com deficiência (ARAÚJO, 2011).

Outrossim, cumpre destacar que a Convenção preconizou, em seu preâmbulo, "que a discriminação contra qualquer pessoa, por motivo de deficiência, configura violação da dignidade e do valor inerentes ao ser humano", sendo que para não deixar qualquer dúvida quanto ao que venha ser considerado "discriminação por motivo de deficiência", a própria Convenção trouxe a definição do termo no artigo $2^{\circ 4}$.

A partir da análise da evolução da legislação internacional sobre os direitos das pessoas com deficiência, é possível identificar que houve uma mudança de perspectiva com o objetivo de incluir essas pessoas na sociedade. Nesse sentido, os primeiros documentos internacionais além de não serem considerados fontes formais, uma vez que não criavam normas jurídicas obrigatórias, concentravam-se no modelo médico, o que acabava por produzir, na prática, a segregação das pessoas com deficiência.

Assim, fica nítida a nova preocupação da comunidade internacional em promover a inclusão das pessoas com deficiência quando, primeiramente, por meio da Convenção Interamericana sobre a Eliminação de todas as formas de Discriminação contra Pessoas com Deficiência, passa a tratar a deficiência como um conceito que pode se agravar de acordo com o tratamento que a sociedade confere a esses indivíduos. Contudo, registre-se que este Tratado Internacional possuía alcance limitado, já que foi produzido no âmbito do Sistema Regional Americano de Direitos Humanos, alcançando, quando muito, tão somente os Estados-membros da Organização dos Estados Americanos.

\footnotetext{
${ }^{4}$ Art. 2. [...] "Discriminação por motivo de deficiência" significa qualquer diferenciação, exclusão ou restrição baseada em deficiência, com o propósito ou efeito de impedir ou impossibilitar o reconhecimento, o desfrute ou o exercício, em igualdade de oportunidades com as demais pessoas, de todos os direitos humanos e liberdades fundamentais nos âmbitos político, econômico, social, cultural, civil ou qualquer outro. Abrange todas as formas de discriminação, inclusive a recusa de adaptação razoável;
} 
Nesse contexto, foi necessário aprovar, no ano de 2006, a Convenção Internacional sobre os Direitos das Pessoas com Deficiência, com vistas a corroborar, no âmbito da ONU, a perspectiva de que a deficiência não deve ser tratada como doença.

Mas, afinal, que espécie de direitos a Convenção da ONU sobre os Direitos das Pessoas com deficiência procurou proteger?

Primeiramente, vale dizer que a Convenção Internacional da ONU sobre os Direitos das Pessoas com Deficiência visa a combater a ótica neoliberal, uma vez que buscou efetivar um sistema misto de direitos em igualdades de condições - direitos civis e sociais - (SANJOSÉ GIL, 2007). Outro ponto a ser destacado consiste na participação decisiva de Organizações não Governamentais representantes das Pessoas com Deficiência na elaboração do texto da Convenção, no intuito de que fosse desenvolvido um documento de proteção aceitável e condizente com as reais necessidades desses indivíduos, no melhor estilo de consagração do lema "nada sobre nós, sem nós"5.

Importa salientar que a principal instituição representante das pessoas com deficiência que participou decisivamente do processo de elaboração da Convenção foi a International Disability Alliance (IDA), que se constitui em um consórcio de sete organizações, que são: a União Mundial de Cegos; a União Mundial de Surdos; a União Mundial de Surdos e Cegos; a Rede Mundial de Utilizadores e Sobreviventes da Psiquiatria; a Inclusão Internacional; a Disabled People International; e a Rehabilitation International (CHAMBERLIN, 2005).

A partir desses elementos, é possível identificar que a Convenção sobre os Direitos das Pessoas com Deficiência consagrou direitos civis, políticos, econômicos, sociais e culturais, na afirmação da perspectiva integral dos direitos humanos (PIOVESAN, 2012), não havendo que se falar em nenhuma inovação quanto ao reconhecimento de novos direitos específicos. O que se buscou, pois, foi promover a igualdade em seu sentido material.

Dessa forma, é possível assinalar que além de promover a igualdade por meio do respeito às diferenças, a Convenção adota um verdadeiro "processo comunitário participativo" (WOLKMER, 2006, p.117) no que toca às entidades não governamentais representantes dos

\footnotetext{
${ }^{5}$ O lema "nada sobre nós sem nós" consolidou-se a partir de 1981, quando foi comemorado o Ano Internacional das Pessoas com Deficiência. A essência do lema consiste no fato de que as pessoas com deficiência não aceitam que nenhuma política seja decidida por qualquer instituição da sociedade em geral (pública ou privada), ainda que em seu benefício, sem a plena e direta participação das próprias pessoas com deficiência. $C f$. SASSAKI, Romeu Kazumi. Nada sobre nós, sem nós: da integração à inclusão - Parte 1. Revista Nacional de Reabilitação, ano X, n. 57, jul./ago. 2007, p. 8-16.
} 
das pessoas com deficiência, haja vista que os Estados, de forma isolada, não teriam condições de elaborar um texto que atendesse às reais necessidades desses indivíduos.

\section{OS DIREITOS DAS PESSOAS COM DEFICIÊNCIA NO PLANO INTERNO}

No plano do Direito interno brasileiro, em que pese as diferentes correntes doutrinárias e jurisprudenciais existentes quanto à hierarquia normativa dos tratados internacionais de direitos humanos incorporados ao ordenamento jurídico pátrio, importa considerar que a Convenção sobre os Direitos das Pessoas com Deficiência foi aprovada por meio do Decreto Legislativo $\mathrm{n}^{\circ} 186$, de 09 de julho de 2008 , seguindo o rito do $\S 3^{\circ}$ do art. $5^{\circ}$, da Constituição Federal, o que lhe confere estatura de norma formalmente constitucional.

Dessa forma, ainda que não tenha sido escrita pelo legislador constituinte e não esteja redigida de forma expressa em seu texto, a Convenção Internacional sobre os Direitos das Pessoas com Deficiência integra a Constituição Federal da República Federativa do Brasil.

Por oportuno, antes de procurar debater acerca dos reflexos da Convenção Internacional sobre os Direitos das Pessoas com Deficiência, é mister discorrer acerca do status dos tratados internacionais de direitos humanos que ingressam no sistema normativo brasileiro. Para tanto, vale-se do que preconiza o art. $5^{\circ}, \S 2^{\circ}$, da Constituição Federal, que estabelece que "os direitos e garantias expressos nesta Constituição não excluem outros decorrentes do regime e dos princípios por ela adotados, ou dos tratados internacionais em que a República Federativa do Brasil seja parte".

A par disso, eis que doutrina e jurisprudência, de forma significativa, entendiam que os tratados internacionais tradicionais possuíam força hierárquica de norma infraconstitucional, ao passo que os tratados internacionais de direitos humanos constituir-se-iam em norma de hierarquia constitucional. Contudo, com o advento da Emenda Constitucional no 45/2004, que acrescentou o $\S 3^{\circ}$ ao artigo $5^{\circ}$ da Constituição Federal, ${ }^{6}$ a discussão sobre a matéria foi retomada, e doutrina e jurisprudência passaram a discordar.

Em que pese o tema suscitar divergência de posicionamento, para significativa parte da doutrina, os tratados internacionais de direitos humanos seriam, de qualquer sorte, materialmente constitucionais, apresentando apenas a variação de formalmente constitucionais,

\footnotetext{
${ }^{6}$ Art. $5^{\circ}[\ldots] \S 3^{\circ}$ Os tratados e convenções internacionais sobre direitos humanos que forem aprovados, em cada Casa do Congresso Nacional, em dois turnos, por três quintos dos votos dos respectivos membros, serão equivalentes às emendas constitucionais.
} 
dado o rito de aprovação quando incorporados ao ordenamento jurídico interno brasileiro (EMERIQUE e GUERRA, 2008). Tal posicionamento coaduna com o magistério de Celso Lafer, que entende que a partir da Emenda Constitucional $n^{\circ} 45 / 2004$, para que os tratados internacionais de direitos humanos sejam reconhecidos formalmente como normas constitucionais devem obedecer ao rito do parágrafo $3^{\circ}$, do artigo $5^{\circ}$ da Constituição Federal (LAFER, 2005).

Nesse contexto, consigna-se que a jurisprudência atual adota a ideia de que os tratados de direitos humanos incorporados ao ordenamento jurídico brasileiro sem a observância pro forme do disposto no $\S 3^{\circ}$, do art. $5^{\circ}$, da Constituição Federal, possuem a natureza de norma supralegal, ou seja, estariam abaixo da Constituição, mas acima das leis ordinárias. Tal entendimento foi concebido no STF, a partir do voto do Ministro Sepúlveda Pertence no RHC $\mathrm{n}^{\mathrm{o}}$ 79785-RJ, consolidando-se, no entanto, por meio do voto do Ministro Gilmar Mendes no RE 466343, que reconheceu a impossibilidade de prisão do depositário infiel no Brasil porque foi proibida essa modalidade de prisão pelo Pacto de San Jose da Costa Rica de $1969^{7}$.

O Pacto, desde que ratificado, nunca foi considerado inconstitucional (apesar de a Constituição Federal permitir a prisão civil do depositário infiel) porque extinguiu uma das exceções da prisão civil e ampliou o direito constitucional de um indivíduo não ser preso. Hoje não há a prisão do depositário infiel porque o Pacto de San José tem status de supralegalidade e prevalece sobre as normas em sentido contrário.

Assim, a despeito das diferentes correntes doutrinárias e jurisprudenciais existentes quanto à hierarquia normativa dos tratados internacionais de direitos humanos incorporados ao ordenamento jurídico pátrio, principalmente quanto aos que seriam considerados materialmente constitucionais, sem, contudo, vestirem a roupagem de norma formalmente constitucional, importa ratificar que a Convenção sobre os Direitos das Pessoas com Deficiência foi aprovada por meio do Decreto Legislativo $\mathrm{n}^{\circ} 186$, de 09 de julho de 2008, seguindo o rito do $\S 3^{\circ}$ do art. $5^{\circ}$, da Constituição Federal, o que lhe atribui status de norma formalmente e materialmente constitucional.

\footnotetext{
${ }^{7}$ O chamado Pacto de San José da Costa Rica trata-se da Convenção Americana sobre os Direitos Humanos, cujo texto foi concluído em 22 de dezembro de 1969 e entrou em vigor em 18 de julho de 1978. A entidade responsável por garantir sua aplicação é a Corte Interamericana de Direitos Humanos, sediada em San José, na Costa Rica. Assim como os Pactos Internacionais de Direitos Civis e Políticos, Econômicos e Sociais, de 1966, o Pacto de San José da Costa Rica foi adotado com status de norma cogente com vistas a proteger os direitos humanos, sendo que seu alcance, contudo, ocorre apenas no âmbito da Organização dos Estados Americanos. Cf. REZEK, José Francisco. Direito internacional público: curso elementar. 15. ed. rev. e atual. São Paulo: Saraiva, 2014, p. 256257.
} 


\subsection{Terminologia constitucional}

Inicialmente, no que se refere aos termos empregados pela legislação nacional para identificar as pessoas com deficiência, convém destacar três expressões constitucionais: excepcional, deficiente e pessoas portadoras de deficiência (ARAÚJO, 2011).

A expressão excepcional foi a primeira a ser utilizada no âmbito da proteção específica destinada a pessoas com deficiência, por meio da promulgação da Emenda Constitucional $n^{\circ} 1$, de 1969, à Constituição Federal de 1967. No contexto em que foi empregado, Francisco Pontes de Miranda entendia o termo excepcional para designar as pessoas que, em razão de deficiência física ou mental, ou mesmo, por carência social, necessitassem de assistência (PONTES DE MIRANDA, 1970).

Não obstante, conforme adverte Luiz Alberto Araújo, a expressão em análise é inadequada ou desaconselhável, uma vez que apresenta forte tendência para referir-se, tão somente, a pessoas com deficiência mental, não abarcando, por conseguinte, as deficiências físicas, entre outras. Ademais, para o autor, os carentes sociais não se enquadrariam na ideia de pessoa com deficiência, uma vez que dispõem de todas as capacidades para atingir seus objetivos (ARAÚJO, 2011).

O termo excepcional foi empregado constitucionalmente até outubro de 1978, quando a então Emenda Constitucional $\mathrm{n}^{\circ} 12$ passou a adotar a expressão deficiente. Segundo Manoel Gonçalves Ferreira Filho, a palavra deficiente define aqueles que se encontram aquém da normalidade em termos de capacidade física e mental (FERREIRA FILHO, 1983).

Nesse ponto, vale destacar o caráter incisivo do termo deficiente, pois concentra-se demasiadamente na deficiência do indivíduo. Em outras palavras, ressalta o estigma da deficiência ao mesmo tempo em que reduz o conceito de pessoa, que se aplica apenas aos que se apresentam como indivíduos tipicamente "normais".

Prosseguindo cronologicamente, já sob a vigência da Constituição Federal de 1988, introduziu-se a expressão pessoa portadora de deficiência, que, de acordo com Luiz Alberto Araújo, tem como núcleo a palavra pessoa, sendo o termo deficiência um mero qualificativo. Dessa forma, a expressão utilizada aqui é mais leve, já que ressalta o conceito de pessoa e mitiga a suposta desvantagem que se atribui aos indivíduos nessa situação (ARAÚJO, 2011).

Cumpre ressaltar que a Convenção sobre os Direitos das Pessoas com Deficiência passou a adotar a expressão pessoa com deficiência. Assim, considerando o status hierárquico 
normativo deste documento no plano interno, a expressão passou a ser a mais adequada atualmente.

O núcleo da expressão continua sendo o termo pessoa, que, em vez de portar, tem uma deficiência (ARAÚJO, 2011). Contudo, ainda é possível encontrar grande parte dos textos constitucionais utilizando a expressão pessoa portadora de deficiência, o que não seria o correto, tendo em vista a incorporação dos termos da Convenção.

\subsection{Legislação nacional e paradigmas adotados}

A fim de identificar a adoção dos paradigmas acerca dos direitos das pessoas com deficiência em diferentes momentos, importa citar alguns dispositivos legais, constitucionais e infraconstitucionais. No caso do texto constitucional, destacam-se, primeiramente, os seguintes dispositivos, todos com redação anterior à vigência da Convenção sobre os Direitos das Pessoas com Deficiência no plano interno, que se deu por meio da promulgação do Decreto $\mathrm{n}^{\circ} 6.949$, de 25 de agosto de 2009:

CF/1988.

$[\ldots]$

Art. 24. Compete à União, aos Estados e ao Distrito Federal legislar concorrentemente sobre:

XIV -proteção e integração social das pessoas portadoras de deficiência; $[\ldots]$

Art. 203. A assistência social será prestada a quem dela necessitar, independentemente de contribuição à seguridade social, e tem por objetivos:

IV - a habilitação e reabilitação das pessoas portadoras de deficiência e a promoção de sua integração à vida comunitária;

$[\ldots]$

Art. 208. O dever do Estado com a educação será efetivado mediante a garantia de:

III - atendimento educacional especializado aos portadores de deficiência, preferencialmente na rede regular de ensino;

A partir da análise dos dispositivos citados, verifica-se que, antes da vigência da Convenção no plano interno, o texto constitucional adotava, explicitamente, o paradigma da integração no que se refere aos direitos das pessoas com deficiência no Brasil. Ainda que se possa eventualmente considerar o art. 208, inciso III, acima exposto, como um dispositivo com vistas à inclusão das pessoas com deficiência, o termo "preferencialmente na rede regular de ensino" corrobora o entendimento de que não há um manifesto compromisso para com a 
inclusão dessas pessoas, pois não se vislumbra uma obrigatoriedade de adaptação do sistema educacional convencional, a fim de atender as condições atípicas dos alunos com deficiência.

Prosseguindo a análise do texto constitucional no que se refere aos paradigmas adotados acerca dos direitos das pessoas com deficiência, é de se lamentar o seguinte dispositivo, com redação dada pela Emenda Constitucional nº 65/2010 (já após a vigência da Convenção sobre os Direitos das Pessoas com deficiência no plano interno), in verbis:

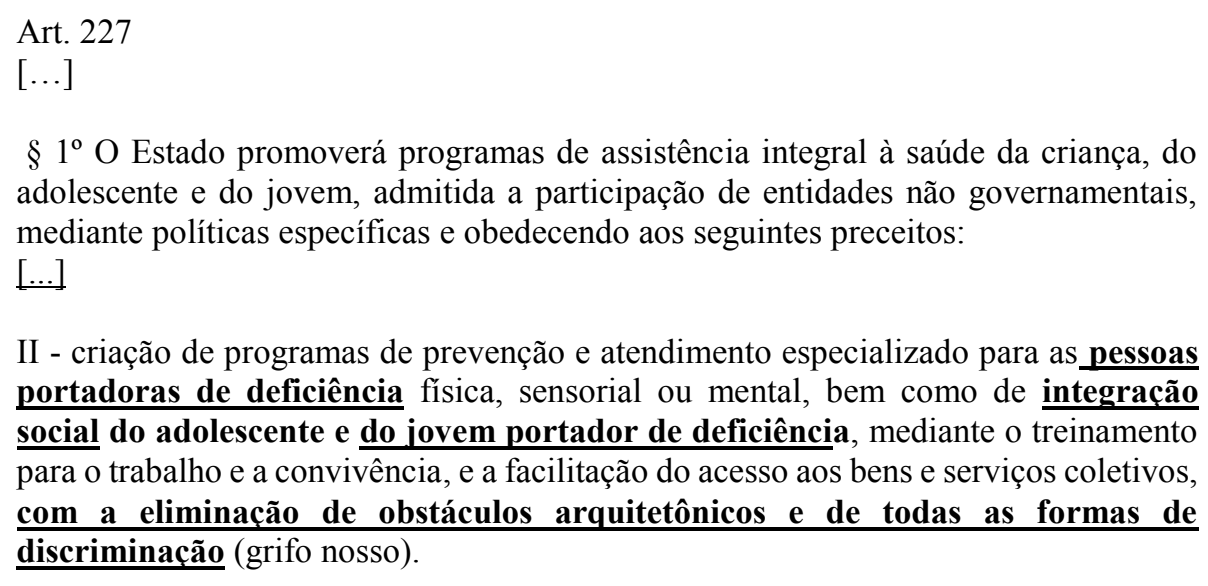
adolescente e do jovem, admitida a participação de entidades não governamentais, mediante políticas específicas e obedecendo aos seguintes preceitos:

II - criação de programas de prevenção e atendimento especializado para as pessoas portadoras de deficiência física, sensorial ou mental, bem como de integração social do adolescente e do jovem portador de deficiência, mediante o treinamento para o trabalho e a convivência, e a facilitação do acesso aos bens e serviços coletivos, com a eliminacão de obstáculos arquitetônicos e de todas as formas de discriminação (grifo nosso).

Conforme se depreende da leitura do dispositivo destacado, nem o status de norma formalmente constitucional da Convenção sobre os Direitos das Pessoas com Deficiência fez com que o próprio legislador constituinte (derivado), ou seja, o mesmo Congresso Nacional responsável pela aprovação da Convenção, empregasse, posteriormente, a terminologia adequada no que se refere às pessoas com deficiência. Além disso, a redação do dispositivo em debate pecou, novamente, quando mencionou o paradigma da integração social como um dos preceitos a ser observado nas políticas públicas voltadas para os jovens com deficiência.

Ora, de acordo com o que foi estudado, o termo pessoa portadora de deficiência não condiz com a terminologia a ser utilizada para referir-se às pessoas com deficiência, mormente levando-se em conta o que preconiza a Convenção sobre os Direitos das Pessoas com Deficiência. Ademais, conforme já visto, o paradigma adotado pela Convenção é o da inclusão social, sendo que, no atual contexto, o paradigma da integração representa um modelo superado.

Assim, tendo em vista a inobservância desses dois aspectos, constata-se, no mínimo, uma falta de rigor técnico por parte do legislador, já que a redação do dispositivo em apreço foi promulgada pela Emenda Constitucional n ${ }^{0}$ 65/2010, após, portanto, à vigência da Convenção no plano interno. Como ponto positivo, embora sem o devido cuidado terminológico, o dispositivo introduziu elementos relacionados ao paradigma da inclusão, quando estabeleceu que devam ser eliminados obstáculos arquitetônicos, no intuito de facilitar o acesso a bens e 
serviços coletivos.

Dessa forma, com exceção ao que estabelece a Convenção sobre os Direitos das Pessoas com Deficiência, que, conforme visto, está pautada sob o paradigma da inclusão e possui status de norma formalmente constitucional, não se localiza, de forma explícita, em nenhum outro dispositivo constitucional vigente, o termo inclusão social, no que se refere ao reconhecimento da necessidade de adaptação dos sistemas sociais comuns, a fim de permitir o pleno desenvolvimento das pessoas com deficiência.

Diante disso, há que se salientar, mais uma vez, a importância da Convenção sobre os Direitos das Pessoas com Deficiência, pois, ainda que não fosse necessário ratificar os preceitos trazidos pela Convenção em outros dispositivos constitucionais, tendo em vista que se tratariam de normas de mesma hierarquia, o que se verifica, pela falta de rigor técnico do legislador, vai de encontro à evolução histórica da legislação internacional, que fez com que o próprio Congresso Nacional reconhecesse que a causa das pessoas com deficiência deveria ser pautada sob o paradigma da inclusão.

No âmbito da legislação federal infraconstitucional, com redação original antes da vigência da Convenção sobre os Direitos das Pessoas com Deficiência, destacam-se a Lei ${ }^{\circ}$ 7.853/1989, que dispõe, entre outras providências, sobre a integração social das pessoas portadoras de deficiência, e o seu regulamento, o Decreto ${ }^{\circ} 3.298$, de 20 de dezembro de 1999, que dispõe sobre a Política Nacional para a Integração da Pessoa Portadora de Deficiência. Diante disso, não há dúvidas de que, de acordo com terminologia empregada, o paradigma adotado foi o da integração, mormente devido ao fato de que foram elaborados anteriormente à Convenção.

Vale dizer, ainda, que o Decreto $n^{\circ} 3.298 / 1999$ baseia-se no conceito médico de deficiência e visa, justamente, a estabelecer parâmetros médicos objetivos para determinar se o indivíduo pode ser considerado pessoa portadora de deficiência ${ }^{8}$, segundo as diferentes categorias possíveis, que são: deficiência física; deficiência auditiva; deficiência visual; deficiência mental; e deficiência múltipla. Tais parâmetros foram elencados no art. $4^{\circ}$ do Decreto, cuja redação sofreu alterações pelo Decreto ${ }^{\circ}$ 5.296/2004.

Em contrapartida, o Decreto faz referência expressa ao paradigma da inclusão em diversos dispositivos, conforme segue:

Art. 6o São diretrizes da Política Nacional para a Integração da Pessoa Portadora de Deficiência:

${ }^{8}$ De acordo com a terminologia adotada pelo Decreto no $3.298 / 1999$. 
I - estabelecer mecanismos que acelerem e favoreçam a inclusão social da pessoa portadora de deficiência;

$[\ldots]$

Art. 7 $\underline{\text { o }}$ São objetivos da Política Nacional para a Integração da Pessoa Portadora de Deficiência:

II - integração das ações dos órgãos e das entidades públicos e privados nas áreas de saúde, educação, trabalho, transporte, assistência social, edificação pública, previdência social, habitação, cultura, desporto e lazer, visando à prevenção das deficiências, à eliminação de suas múltiplas causas e à inclusão social;

$[\ldots]$

$\mathrm{V}$ - garantia da efetividade dos programas de prevenção, de atendimento especializado e de inclusão social.

$[\ldots]$

Art. 9ọ Os órgãos e as entidades da Administração Pública Federal direta e indireta deverão conferir, no âmbito das respectivas competências e finalidades, tratamento prioritário e adequado aos assuntos relativos à pessoa portadora de deficiência, visando a assegurar-lhe o pleno exercício de seus direitos básicos e a efetiva inclusão social.

$[\ldots]$

Art. 16. Os órgãos e as entidades da Administração Pública Federal direta e indireta responsáveis pela saúde devem dispensar aos assuntos objeto deste Decreto tratamento prioritário e adequado, viabilizando, sem prejuízo de outras, as seguintes medidas:

VI - o desenvolvimento de programas de saúde voltados para a pessoa portadora de deficiência, desenvolvidos com a participação da sociedade e que lhes ensejem a inclusão social;

$[\ldots]$

Art. 19. Consideram-se ajudas técnicas, para os efeitos deste Decreto, os elementos que permitem compensar uma ou mais limitações funcionais motoras, sensoriais ou mentais da pessoa portadora de deficiência, com o objetivo de permitir-lhe superar as barreiras da comunicação e da mobilidade e de possibilitar sua plena inclusão social.

A partir da leitura dos dispositivos citados, visualiza-se, novamente, uma falta de rigor técnico por parte do legislador, que, por vezes, parece tratar os termos integração e inclusão como sinônimos. Positivamente, poder-se-ia dizer que o Decreto, mesmo adotando o paradigma da integração, tem por objetivo alcançar a inclusão social por meio de mecanismos que acelerem esse processo.

Ainda que se possa considerar que o termo integração tenha sido empregado erroneamente, e que o conteúdo do Decreto cuide especificamente dos aspectos relacionados à 
inclusão social, o foco da deficiência continua centrado no indivíduo, principalmente porque leva em consideração o modelo médico para definir quem é pessoa com deficiência, em detrimento de aspectos sociais que contribuem para esse fator.

No âmbito da legislação infraconstitucional, o marco para adoção do paradigma da inclusão social, no que se refere aos direitos das pessoas com deficiência, foi a edição da Lei $\mathrm{n}^{\circ}$. 13. $146^{9}$, de 06 de julho de 2015, que instituiu o Estatuto da Pessoa com Deficiência, em vigor desde 06 de janeiro de 2016. Como principal objetivo, o Estatuto visa a assegurar o exercício dos direitos fundamentais das pessoas com deficiência em igualdade de condições com os demais, a fim de promover a inclusão social desses indivíduos.

\section{DA EXCLUSÃO À INCLUSÃO?}

Conforme destaca Romeu Sassaki, a exclusão consiste, quando se leva em conta as diversas fases concernentes a práticas sociais, em um estágio inicial que levou em consideração que pessoas que apresentavam condições atípicas pareciam não pertencer à maioria da população. A par disso, o autor assevera que as referidas condições atípicas podem manifestarse, dentre outras, das seguintes formas: deficiências mental, física, auditiva, visual e múltipla; dificuldades de aprendizagem; insuficiências orgânicas; problemas de conduta; distúrbio de déficit de atenção com hiperatividade; distúrbios emocionais; transtornos mentais etc (SASSAKI, 1999).

Em paralelo, há que se registrar que algumas das condições atípicas são criadas ou agravadas justamente por conta de práticas sociais excludentes, tais como: trabalho infantil, prostituição, pobreza, desnutrição, saneamento precário, falta de escolaridade etc. Corroborase a esse argumento o fato de que o índice de pessoas com deficiência no Brasil não possui a mesma causa dos países desenvolvidos, uma vez que se deve, muitas vezes, "à carência alimentar e à falta de condições de higiene" (ARAÚJO, 2011, p. 8).

\footnotetext{
${ }^{9}$ Lei ${ }^{\circ}$. 13. 146, de 06 de julho de 2015 [...] Art. $1^{\circ}$ É instituída a Lei Brasileira de Inclusão da Pessoa com Deficiência (Estatuto da Pessoa com Deficiência), destinada a assegurar e a promover, em condições de igualdade, o exercício dos direitos e das liberdades fundamentais por pessoa com deficiência, visando à sua inclusão social e cidadania. Parágrafo único. Esta Lei tem como base a Convenção sobre os Direitos das Pessoas com Deficiência e seu Protocolo Facultativo, ratificados pelo Congresso Nacional por meio do Decreto Legislativo $\mathrm{n}^{\circ} 186$, de 09 de julho de 2008, em conformidade com o procedimento previsto no $\S 3^{\circ}$ do art. $5^{\circ}$ da Constituição da República Federativa do Brasil, em vigor para o Brasil, no plano jurídico externo, desde 31 de agosto de 2008, e promulgados pelo Decreto $\mathrm{n}^{\circ} 6.949$, de 25 de agosto de 2009 , data de início de sua vigência no plano interno.
} 
Verifica-se, dessa forma, que as condições atípicas apresentadas por certos indivíduos nem sempre decorrem de sua situação biológica, mas também do contexto social em que estão inseridos. Como alternativa, a prática da inclusão social surge como um processo ambivalente, na medida em que permite que pessoas que se encontrem em situação de exclusão busquem, em conjunto com a sociedade, encontrar soluções que visem à equiparação de oportunidades para todos.

Não obstante, para além da concepção de que para ser incluído deve-se, primeiramente, ser considerado excluído, vale destacar que, dada a complexidade da sociedade atual, há variáveis que se apresentam acerca do tema. Por conseguinte, a distinção binária inclusão/exclusão não seria mais condizente com as múltiplas interações sistêmicas e as complexas relações sociais que se apresentam na contemporaneidade (MASCAREÑO, 2014).

Nesse sentido, Marcelo Neves assevera que a problemática que envolve a concretização de um Estado de Direito nos países periféricos não consiste em superar a exclusão por meio da inclusão, mas sim a generalização das posições de subinclusão de uns, para os quais se atribui somente deveres, e a sobreinclusão de outros, para os quais se garante a efetividade de direitos sem que sofram a atividade punitiva do Estado na eventualidade de não cumprirem com seus deveres e responsabilidades. Assim, o termo exclusão, por si só, não comporta a complexidade do fato que tanto os subincluídos quanto os sobreincluídos estariam excluídos do Direito, uma vez que se posicionariam abaixo e acima do Direito, respectivamente (NEVES, 2011).

Ainda devido à incapacidade de descrição das complexas relações sociais a partir da distinção terminológica inclusão/exclusão, Aldo Mascareño propõe outras distinções conceituais que merecem ser analisadas, quais sejam: autoinclusão/autoexclusão, inclusão por risco/exclusão por perigo, inclusão compensatória e inclusão na exclusão.

A autoinclusão/autoexclusão consiste na capacidade e na oportunidade que a pessoa tem, de forma individualizada, de decidir acerca de sua própria inclusão ou exclusão em determinado sistema social (MASCAREÑO, 2014), o que se verifica com maior clareza em sociedades periféricas que apresentam altos índices de desigualdade e serviços sociais precarizados. Isto é, de acordo com a capacidade financeira de cada um, identificam-se diferentes níveis de autonomia individual para proporcionar inclusão ou exclusão, já que indivíduos que possuem mais recursos financeiros podem optar por usufruir serviços privados, como saúde e educação, em situação totalmente diferenciada daqueles que se encontram em uma posição financeira desprovida. 
Já a inclusão por risco/exclusão por perigo concentra-se na distinção que se estabelece entre a inclusão/exclusão no processo decisório acerca de determinado tema e a ocorrência de eventuais danos futuros reflexos das decisões tomadas (MASCAREÑO, 2014). Assim sendo, valendo-se da oposição entre os conceitos de risco e perigo em Niklas Luhmann, quem participa das decisões assume o risco de sua própria decisão, uma vez que poderia decidir de forma diversa e não sofrer determinadas consequências, ao passo que quem está excluído desse processo encontra-se em uma situação de perigo, já que não pode optar por não sofrer as consequências das decisões alheias.

Diante dessas considerações, identifica-se que nem mesmo os incluídos no processo decisório estão imunes a sofrer eventuais consequências negativas, eis que escolher a suposta melhor decisão em determinado momento pode mostrar-se inadequada posteriormente, principalmente quando se leva em conta a velocidade e a complexidade das transformações sociais que se manifestam hodiernamente. Nestes termos, a complexidade impõe seleção dentre inúmeras possibilidades para além das que se podem realizar, o que pressupõe o risco de a escolha feita gerar desapontamento (LUHMANN, 1991).

A inclusão compensatória, por seu turno, visa a restabelecer a capacidade de seletividade dos indivíduos que se encontram na posição de autoexcluídos, por falta de recursos monetários, e de excluídos por perigo. Por conseguinte, neste cenário, as ofertas de inclusão visam a limitar os efeitos da exclusão. Contudo, como ponto negativo, há que se registrar que aceita o fato de que a desigualdade possui matriz institucional, na medida em que reconhece a existência de diferentes categorias sociais com capacidade de seletividade diversa, o que leva, ao fim e ao cabo, à promoção da inclusão na exclusão (MASCAREÑO, 2014).

Dessa forma, a inclusão na exclusão, que decorre da inclusão compensatória, consistiria na inclusão da pessoa, mas em uma posição subordina em relação a outras que seriam, em princípio, iguais, o que banaliza a desigualdade como um produto das próprias instituições a partir da ideia de que a estratificação social é vista como um elemento natural (MASCAREÑO, 2014). Nesse contexto, nem mesmo a inclusão afastar-se-ia da tendência de reproduzir a desigualdade enraizada nos países periféricos. 


\section{CONCLUSÃO}

No que concerne aos direitos das pessoas com deficiência, verificou-se que o paradigma da integração social toma por base a ideia de que são as pessoas com deficiência que devem adaptar-se aos sistemas sociais comuns, de modo que, na hipótese de isso não ocorrer, seria necessária a criação de sistemas sociais especiais, separados dos demais, que fossem a elas destinados. Assim, segundo esse paradigma, a estrutura da sociedade não sofre nenhuma alteração significativa, já que continua a oferecer, basicamente, os mesmos serviços.

Por seu turno, o paradigma da inclusão social concentra-se em permitir o convívio das pessoas com deficiência com o resto da sociedade, partindo-se da concepção de que a deficiência não deve ser tratada como doença, mas como manifestação da diversidade humana. Para tanto, pressupõe que a sociedade deve passar por adaptações, a fim de atender às necessidades das pessoas que se encontram excluídas dos sistemas sociais comuns existentes.

Em termos legislativos, constatou-se que tanto a legislação internacional quanto a legislação nacional adotaram, em diferentes momentos, os paradigmas da integração e da inclusão, conforme o contexto em que foram elaboradas.

Diante disso, a aprovação da Convenção Internacional sobre os Direitos das Pessoas com Deficiência, no âmbito da ONU, justificou-se pela inexistência, até então, de um texto internacional vinculante que fosse destinado à proteção dos direitos das pessoas com deficiência, capaz de reivindicar validade universal perante a sociedade internacional. Além disso, foi por meio da Convenção que se universalizou o conceito de deficiência a partir de um enfoque social, que significa que a deficiência não está centrada na pessoa, mas na própria sociedade, que impõe limites e barreiras ao pleno desenvolvimento das pessoas com deficiência, consagrando, assim, o reconhecimento do paradigma da inclusão como o mais adequado.

Por fim, ainda que a prática da inclusão social tenha surgido como um processo ambivalente, na medida em que permite que pessoas que se encontrem em situação de exclusão busquem, em conjunto com a sociedade, encontrar soluções que visem à equiparação de oportunidades, vale destacar que, dada a complexidade da sociedade atual, há variáveis que se apresentam acerca do tema.

Por conseguinte, a distinção binária inclusão/exclusão não seria mais condizente com as múltiplas interações sistêmicas e as complexas relações sociais que se apresentam na contemporaneidade, uma vez que nem mesmo a inclusão afastar-se-ia da tendência de reproduzir a desigualdade enraizada nos países periféricos. 
José Alberto Antunes de Miranda \& Reynaldo Alan Castro Filho

\section{REFERÊNCIAS}

ARAÚJO, Luiz Alberto David. A proteção constitucional das pessoas com deficiência. Ministério da Justiça: Brasília, 4ª ed. rev. ampl. e atual, 2011.

CHAMBERLIN, Judi. A defesa dos direitos das pessoas com doença mental: desenvolvimento de uma perspectiva de direitos humanos In: ORNELAS, José et al. (org.). Participação e Empowerment das Pessoas com Doença Mental e seus Familiares. Lisboa: AEIPS Edições, 2005.

EMERIQUE, Lilian Balmant et al. A incorporação dos tratados internacionais de direitos humanos na ordem jurídica brasileira In: Revista Jurídica, Brasília. v. 10, n. 90, Ed. Esp, abr./maio, 2008.

FERNÁNDEZ LIESA, Carlos R. Codificación internacional y desarrollo progresivo de los derechos humanos de las personas con discapacidad In: FERNÁNDEZ LIESA, Carlos R., (coord.). La protección internacional de las personas com discapacidad. Madrid: BOE, 2007.

FERREIRA FILHO, Manoel Gonçalves. Comentários à Constituição Brasileira: emenda constitucional $\mathrm{n}^{\circ} 1$, de 17 de outubro de 1969, atualizado até a Emenda Constitucional $\mathrm{n}^{\circ} 22$, de 29 de junho de 1982. rev. atual. São Paulo: Saraiva, $3^{\text {a }}$. Ed, 1983.

FLETCHER, Agnes. Ideias práticas em apoio ao Dia Internacional das Pessoas com Deficiência: 3 de dezembro. Tradução por: Romeu Kazumi Sassaki. São Paulo: PRODEFIAPADE, 1996.

LAFER, Celso. A internacionalização dos direitos humanos: constituição, racismo e relações internacionais. São Paulo: Manole, 2005.

LORENTZ, Lutiana Nacur. A norma da igualdade e o trabalho das pessoas portadoras de deficiência. 2. ed., São Paulo: LTr, 2016.

LUHMANN, Niklas. Sociologia del riesgo. México: Universidad Iberoamerica; Universidad de Guadalajara, 1991

MASCAREÑO, Aldo. Diferenciación, inclusión/exclusión y cohesión en la sociedad moderna. Revista Cis, p. 8-25, jul./dez. 2014.

MENDES, Enicéia G. Integração escolar: reflexões sobre a experiência de Santa Catarina. In: Interação, v. 5, n. 12, p. 5-16, 1994.

NEVES, Marcelo. Los estados en el centro y los estados en la periferia: algunos problemas con la concepción de estados de la sociedad mundial en Niklas Luhmann. In: NAFARRATE, Javier Torres; MANSILLA, Darío Rodríguez (Ed.). Niklas Luhmann: la sociedad como pasión: aportes a la teoría de la sociedad de Niklas Luhmann. México: Universidad Iberoamericana, 2011.

PIOVESAN, Flávia. Temas de direitos humanos. 5. ed. São Paulo: Saraiva, 2012.

Rev. de Direito Sociais e Políticas Públicas | e-ISSN: 2525-9881 | Porto Alegre | v. 4 | n. 2 | p. 1 - 21 | Jul/Dez. 2018 
PONTES DE MIRANDA, Francisco Cavalcanti. Comentários à Constituição de 1967, com a Emenda no 1. de 1969. São Paulo: Ed. Revista dos Tribunais, 1972, vol. 6.

REZEK, José Francisco. Direito internacional público: curso elementar. 15. ed. rev. e atual. São Paulo: Saraiva, 2014.

ROBERTSON, Nancy, BAROUSSE, Melody, SQUIRES, Stephanie. Answering your questions about inclusive education. New Orleans: Louisiana Clearinghouse for Inclusive Education, 1995.

SANJOSÉ GIL, Amparo. El primer tratado de derechos humanos del siglo XXI: la convención sobre los derechos de las personas con discapacidad. Revista electrónica de estudios internacionales, $\mathrm{n}^{\circ} 13$, junho, 1997.

SASSAKI, Romeu Kazumi. Inclusão: construindo uma sociedade para todos. Rio de Janeiro: WVA, 1997.

. Nada sobre nós, sem nós: da integração à inclusão - Parte 1. In: Revista Nacional de Reabilitação, ano X, n. 57, jul./ago. 2007.

Reabilitação, jul/ago. 2004.

Pessoas com deficiência e os desafios da inclusão. In: Revista Nacional de

WOLKMER, Antonio Carlos. Pluralismo jurídico, direitos humanos e interculturalidade In: Revista Sequência, nº 53, p. 113-128, dez. 2006. 